IBT Journal of Business Studies

Volume 14(2), 221-240, 2018

\title{
Phenomenological Study of Gender Diversity at a Pakistani Organization
}

\author{
Tazeen Imran $^{1}$ \\ Sara Khan ${ }^{2}$ \\ Nazia Saeed ${ }^{3}$
}

\begin{abstract}
This research aims to improve an understanding of the lived experience of the gender diversity of respondents in the Pakistani context. It provides a rich description of the influence that gender diversity had on the organizational culture and the employees. Specific benefits anticipated by the organization, from implementation of gender diversity and related challenges were explored. Indepth interviews were conducted with key personnel including HR managers assigned with a specific task to implement gender diversity across the organization. The findings reveal that a lot of concentrated efforts have been put in to eradicate the mental barriers within the system and also inculcate the culture of diverse sets of people, especially gender, allowing multiple and diverse opinions within the organization. Targeted efforts towards gender diversity have started showing its fruits; as such implementation has led to improved performance for the organizations and creation of job opportunities for the female gender, which may have been ignored earlier. Moreover, the organization strongly believes that ongoing efforts will yield better results. Therefore focused efforts, initiatives and constant messages to change the mindset need to continue. The trustworthiness of the data will be established through triangulation and a chain of evidence has been established between the research objective, research questions and the interview data.
\end{abstract}

Keywords: Gender Diversity, Phenomenology, Organizational culture, Pakistan

1- Lecturer at Szabist, Karachi, Pakistan, tazeen.imran@szabist.edu.pk

2- IBA, PhD, Karachi, Pakistan, sarumb@gmail.com

3- Lecturer, Ilma University, nazia@ilmauniversity.edu.pk 


\section{INTRODUCTION}

Diversity in the organization means that the company understands and relates that its people are different. They are different in race, age, gender, culture and disability etc. and it is the ability of the organization to make best use of the diverse work group and make them its company's strength, power and beneficial. Organizations seeking to excel in the future realize the fact that skilled employees and managers are required to deal with these diversities (Milliken \& Martins, 1996). Diversity is mostly taken as race, and gender but it is much broader than this as it implies all those qualities which a human possess and is different in every individual or to a group that we belong and interact with. The important aspect is that how these diverse people are put together to obtain motivation, success, a need for personal development which ultimately benefits the overall goals and objectives of the organization. Internationally a lot of work has been done on diversity but unfortunately it is an under researched area in Pakistan. The topic has been selected to understand the lived experiences of individuals as a part of diversity in the organization.

There was a growing recognition of diversity by the late 1970s and into 1980s by the private sectors where they were engaged in promoting and developing a positive change in the culture of the organization by having a diverse workforce. Many companies started different training programs to change a typical mindset of employees' attitude and behavior towards diversity of all sorts like age, sex, race, color etc. These training programs enhanced interactions and a positive relationship among the employees and provide a vision to understand and value diversity (Kochan, et al.,2003). During the year 1990 the concept took a shift from the relationships to the business performances. By this time it was believed that diversity was not restricted to business image of giving equal opportunities and to fulfill the product market but also it was giving good business results. So they started working on hiring and developing a diverse workforce which not only provide a better environment in terms of attitude and relationship but also give better results. A research found that diverse organizations produce better results. Therefore, process of recruitment, training and other development factors were being revised. A lot of training initiatives have been taken to promote the concept of diversity encouraging employees to believe that other than race and gender there are other differences to value like cultural, physical and interpersonal which plays a vital role in problem solving, creativity and innovation and decision making (Kochan, et al.,2003); (Jayne \& Dipboye, 2004); (Herring, 2009). Over the years, diversity is being recognized as a reality in workforce by business leaders, civil society and government alike. The Civil Rights Act of 1964 made it illegal for companies and other organizations who are engaged in discriminationg employees on the basis of race, cultur, religion, colour, nationality and sex. After this act the organizations started promoting equal employment opportunity to people having similar qualifications. Gradually diversity initiatives start penetrating into organizations and trainings were given to employees encouraging them to value cultural, physical and interpersonal differences, resulting in enhanced problem solving, decision making and creativity and innovation at work (Bezrukova, Jehn, \& Spell, 2012).

Many organizations have realized the need of a diverse workforce and therefore, introduced diversity initiatives, hiring of diversity expert or consultant and also provides various programs on diversity training. Diversity is a core and a key component to bring a positive change in the organization (Stevens, Plaut, \& Sanchez-Burks, 2008).

Considering most companies in Pakistan have not worked towards gender diversity, there exists an untapped market as women bring in a different thought process to the table.

Pakistan is a male dominated society where women are usually considered to be secondary citizens because of many reasons like our traditional norms, sociocultural and economic factors, limited professional choices, religious constraints and lack of other supportive facilities (Ali \& Syed, 2017).

From previous researches it was discern that there are many other factors and reasons why gender 
diversity is considered important to gauge organizational performance. Further the researcher cited the gap that the reason beside performance should also be explored for developing better understanding of diversity and its related impacts (Chapple \& Humphery, 2014).

The literature shows that limited research has been done on understanding the impact of gender diversity on the organizational culture in the context of the Pakistani firm. This research intends to bridge this gap by studying the case of a local conglomerate to develop the understanding of the lived experience of gender diversity in the context of the Pakistani firm. The research also aims to bridge the gap of understanding the aftermaths of gender diversity on organizational members.

The reason for choosing gender diversity as the focus of this research is considering the fact that Pakistan is undergoing a shift in culture with reference to female education and career. Where this is a positive shift, the related responsibilities of managing family and household chores remain with the female. Therefore, a career making female individual has more responsibility on her shoulders.

The objective of this research is to interpret the gender diversity as the lived experience of the respondents' through phenomenological hermeneutics in the context of a Pakistani organization.

The purpose of this study is to understand how gender diversity is enacted in a local conglomerate of Pakistan giving rise to the following research questions:

- What do you understand by gender diversity?

- How do you define gender diversity in your organization?

- How gender diversity has impacted the overall organizational environment and culture?

- How gender diversity has impacted the respondent?

In the recent few years certain Pakistani companies have initiated diversity initiatives out of which gender diversity is the most prominent and common. This study is conducted to describe gender diversity implemented in Pakistani companies. Despite the challenges faced by the women, there is a gradual increase in women participation in the workforce and diversity is still gaining popularity (Ali $\&$ Syed, 2017). The reason for phenomenological study is to understand and describe that how gender diversity is experienced by the respondents and how they perceive their role in overall organizational performance.

\section{LITERATURE REVIEW}

Organizations have always been keen on maximizing profits and focus all their efforts on identifying new technologies and synergies to achieve them. In the recent decades organizations have realized one more important area leading to profit maximization is human resource. Human resource is now being considered as the one of the most critical elements, if not the most, for any organization to prosper and deliver exceptional results. A lot of companies now therefore invest heavily on their human resource be it their benefits, trainings, health etc. so that the employees remain motivated and deliver to their fullest. While focus remains on human resource betterment, the most recent phenomenon in organization is focus on diversity. The focus on human resource has highlighted the importance of varied individuals possessing diverse skill sets. It also explains that how such diverse skill sets when employed together result in better ideas, better risk management and improved profitability. Employing females as part of a workforce brings in the value added mind set and diverse thought process (Beechler \& Woodward, 2009).

\section{Gender diversity}

Gender diversity in the workplace is the acceptance and equal treatment of both females and males in an organization and intends to add value to an organization's results due to the diverse backgrounds 
and views of individuals. There has been a considerable increase in gender diversity as more women are entering into the managerial positions. However, the research has also observed that there has been a negative relationship between gender diversity and firm performance as it becomes difficult to control and coordinate with different people and to bring them towards one goal (Chadwick, 2003). Gender diversity especially in top management positions have been gaining importance in the recent era. There seem to have an immense interest of gender diversity as a value driven concept for researchers and other corporate strategy and governance (Marinova, Plantenga, \&Remery, 2010; Muhammad, NazarKhan, Babar, \& Qalb-e-Abbas, 2016).

In the corporate sector there are few women in the top management because they are considered to be less rational, emotional and are unable to take appropriate strategic decisions. Researchers suggest that companies where there are at least three female directors they have better ethical working standards as compared to male dominating companies. An international survey indicates that Netherland, Japan, India and Pakistan are the nations at bottom five where the number of working women on top managerial positions is the least. This is so because there is a general thinking that women's first priority is family and home while the rest especially work commitment is secondary. It is generally assumed that women work out of genuine commitment and the cultural barrier where specific role has been identified for men and women who decide that female gender has to take the responsibility of home and the male gender will be responsible for earnings and thus neglecting all the talents and working capabilities of female gender (Mirza, Mahmood, Andaleeb, \& Ramzan, 2012).

Since organizations operate increasingly in multicultural and multinational context, understanding the concept of diversity affecting the outcomes like performance, creativity, satisfaction and turnover which have a greater impact on communication, cognitive and symbolic processes. It is not limited here but the trend of using teams to manage work and coordinate in organizations by spending more time with employees and other people outside their job related and functional groups and bringing people of different mindset, skills, training, values and even background at one forum. The research suggests that diversity not only brings great opportunity for organizations but at the same time a big challenge. It provides new and innovative ideas and quality solutions to multiple problems (Milliken \& Martins, 1996).

In this new millennium era we know that diversity is a reality and now the organizations have expanded their business operations to capture the marketplace globally, so it is necessary to have a diverse workforce engaging in different languages, cultures, norms and other aspects for smooth running of the business. (Leary \& Weathington, 2006).

The relationship between diversity, creativity, innovation and competitive advantage has given the business sector to look for situations and factors which can inculcate creativity in individuals. Successful innovation is not possible without creativity. It has been observed that the desired level of quality and output comes from employee skills and knowledge and not because of strong supervision (Jones \& Nigel, 2005; Vegt, Vliert, \& Huang, 2005). In an organization where gender diversity exist the creativity depends on the environment and support from the organization and also the level of acceptance and tolerance on an individual's part and the creativity which lies in his mind using the diverse people and location (Mostret, 2007).

In an era when creativity and flexibility are essential to competitiveness, diversity is the key for the success of an organization. But at the same time it brings workplace challenges like change in power dynamics, differences of opinions, lack of empathy, tokenism barrier, employee participation and inertia (Joplin \& Daus, 1997) 


\section{Diversity and workplace challenges}

While going for diversity initiatives it's necessary for the organization to give a closer look towards the change in organizational culture and behavior. While implementing gender diversity, certain organizations set unrealistic expectations and expect the change to occur overnight. The concept and intent of diversity is not clarified to all individuals, including senior management responsible for its implementation, leading to an environment which is full of confusion and lacks acceptability. Further lack of formal trainings or trainings of poor quality also leads to failures in implementation (Metzier, 2003). While all factors may be considered as important, however organizational clarity on the objectives and taking everyone together as an organizational culture can be categorized as the utmost important.

\section{Measures taken so far}

Diversity is perceived to add value to a company's results due to the diverse backgrounds and viewpoints of individuals. It is not necessary that it means that organizations employee more or less of any gender, race, or even disable etc, but the concept is to give equal opportunity to everyone in the workplace as each individual has its own qualities, strengths and weaknesses.

Although many steps have been taken with respect to diversity, there are other areas which need further attention, including hiring, career management and training and development, therefore diversity is perceived to receive insufficient attention. Many companies are now realizing the importance of a diverse workforce due to which they are reassessing and modifying their hiring and recruitment process. One of the reasons for lack of sufficient attention in the respective area is considered to be the mental block in organizations and their respective managers. Many times it has been observed that employment barriers are created based on personal thought and interpretations rather than conducting a technical and research analysis.

\section{Organizational Portfolio}

The company under study is one of the fastest growing and one of the largest conglomerates in Pakistan having the vision of catering the local needs with products of global standards. Their vision is to be the leader in providing quality products and services in the growing economies in the agricultural-inputs, energy and consumer businesses by delivering their promise on creating value for multiple stakeholders. In this organization success is driven by the combined efforts of skills, knowledge, and expertise which come from dynamic and very talented professionals.

\section{RESEARCH METHODOLOGY}

It covers the components that are necessary for the methodology of this research. The research methodology suggests about the sampling size, data collection tools and methods and analysis. The research problem of the study decides which methodology to choose so that a judgment can be made about the congruence of one methodology to another regarding the research problem (Silverman, 2013).

The research methodology used in this research is case study as the researcher has little control over the context and the focus is on exploring a phenomenon which is linked to the real life matters. Case study gives a rich and extensive data on the phenomenon of real life context where the researcher has to get the information from multiple sources. (Yin, 2009). A case study is selected to do a study on a particular case or having a clear boundary which could be a program, a project, an event, a department, an individual or an organization Case studies can provide vicarious experiences serves as the linkages. It is necessary for the researcher to describe the setting of the case and also to have detailed information to provide an in-depth view of the phenomenon being discussed (Creswell, 1988). Case study is the study of particularity and complexity of a single case, coming to understand its activity 
within important circumstances (Stake, 1995). In this study a qualitative mode of inquiry into a single holistic case has been selected. Single case study because one company is being studied and holistic because that company will be studied in totality (Yin, 2009; Patton, 2015).The researcher in the qualitative study emphasizes on the nuance, contextual sequentiality and the wholeness of the individual (Stake, 1995).

\section{Research Philosophy}

In this study of diversity, a qualitative description is used. The philosophy adopted in this study is "Hermeneutic Phenomenology". The reason for adopting this philosophical method is that it represents a theory of interpretation. Hermeneutic phenomenology focuses on individual's experiences as it is an attempt to unfold the world as experienced by the individual through their life world stories (Kafle, 2011). Heidegger suggested that instead of focusing on people or phenomena the focus should be on the exploration of the lived experience (Flood, 2013). According to (Kafle, 2011) description itself is an interpretative process. Interpretative analysis called as hermeneutical cycle and is used to understand the parts and its linkage with the whole, and to comprehend the whole by interpreting the parts (Howell, An introduction to the philosophy of methodology, 2013).

\section{Research Design}

Research design in any research is the most crucial part as it provides the basic sense and the logical sequence that connects the data with the research questions leading towards the conclusion (Yin, 2009). The tradition of inquiry is descriptive as the researcher has little control over the context and the focus is on describing a phenomenon which is linked to the real life matters. In phenomenology the researcher articulates the experience of people. Through this the researcher enters the field of the participant's perception and to see how they live, display and experience the phenomenon and also to look for the meanings that are experienced by the participants (Creswell, 1988). Therefore, at the time of data collection phenomenology is used and the same is interpreted while data analysis is being done through hermeneutic phenomenology. Single holistic case study research design is used. It is single because one organization is a separate unit of analysis and holistic because the organization is being studied in totality (Yin, 2009). The time horizon of this research is prefixed and planned. A limited period of time is allotted to conduct the research. The data is collected from both Primary and Secondary sources. In this study in-depth interviews are conducted as data collection methods. The primary data is employed by interview schedule. In secondary sources data will be collected from different articles, journals and other materials available on the organization's website.

\section{Unit of Analysis}

In this phenomenological study the unit of analysis is a local conglomerate of Pakistan, where diversity is being practiced. The company has been selected as an exemplary case of implementing gender diversity.

\section{Unit of Data Collection}

Detailed and in-depth interviews from HR and other key personnel both male and female, with relevant knowledge about the gender diversity in organization has been conducted. The idea is to get the deeper understanding of the phenomena being discussed. There is no definite sample size, as the intention is to extract the essence with as many respondents as possible to describe the concept in detail. Data collection interviews were continued until saturation and when no new aspect is adding value to the context.

\section{Sources of Evidence}

The main sources of evidence are interviews. 


\section{Data Collection Process}

\section{Locating Site and individuals}

In this case a local organization is considered where diversity is being practiced. They were being contacted on phone and after a brief introduction seek interview appointment.

\section{Gaining Access and Rapport}

In order to get access and rapport with concerned respondents an informed consent was obtained before conducting the interview. The consent form was sent through e-mail id stating the nature and purpose of the study and requesting their volunteer participation in the study in the form of giving reliable information.

\section{Sampling Design}

The research is based on a local company of Pakistan, operating in Karachi and therefore the population is all the employees of that particular organization. Samples were drawn from purposive sampling. Purposive sampling is used when necessary information is extracted from a specific group of people, who could provide the relevant information (Bougie \& Sekaran, 2010).

\section{Collecting Data}

The data is collected through in-depth interviews and the same was recorded and is transcribed by verbatim along with that memos are also be made accordingly.

\section{Plan of Analysis}

Since the data is qualitative in nature, therefore the data gives a detailed description of the phenomenon being discussed. It is analyzed through themes to develop a detailed analysis of the case. Richard Hycner's thematic methodology has been used for data analysis. According to (Hycner, 1985) the most important step in analyzing the phenomenological interview is to transcribe the tapes and then after using the bracketing the researcher's interpretations and meanings, the researcher has to listen to the interview again in order to make sense of the whole. Then the researcher begins with a rigorous process of reading the interview again to highlight the important words, phrases or sentences. This is giving general meaning to the text while staying as close as possible to the participant's literal data. These general meanings were classified as categories or clusters in order to determine themes derived from the clusters.

\section{Criteria for judging the quality of research design}

Since the research design represent a logical sequence of data leading towards conclusion so it is necessary that the judging quality of the research design should be appropriate and transparent. At the time of data collection construct validity is judged by the use of multiple sources like interviews and information on other relevant documents. A chain of evidence has also been established between the research objectives, research questions and the interview data. Internal validity is judged by explanation building while doing data analysis and by also addressing the rival explanations. Reliability is conducted to minimize the researcher's biasness and in this case the protocol has been developed in such a manner that a detailed and an in-depth information can be gathered to describe the phenomenon and the same has been shown back to the participants to ensure that no addition or deletion of any idea or statement has been made.

\section{Preparation to Collect Case Study Evidence}

According to Creswell (1988), data collection is a series of interconnected activities whose purpose is to collect information from different sources answering the research questions. The qualitative study 
is engaged in series of activities like which people or place to study, how to gain rapport with the participants, sampling technique, data collection tools and how to store the data. In case study multiple sources of data is used.

In case study there is a continuous interaction between the phenomenon being discussed and the data being collected therefore it is important that the researcher should have a sound knowledge in the domain of the research that is taking place. A researcher has to be capable enough to ask appropriate and relevant questions and can interpret the answers. In this case also an informed consent was obtained before conducting the interview. The consent form was sent through e-mail id stating the nature and the purpose of the study and requesting their volunteer participation in the study in the form of giving reliable information and they also have a right to voluntarily withdraw at any given point of time from the study. They were assured that their data will be kept confidential and their names and identity will only be known to the researcher. It was informed that the study will be shared to them once completed.

The interview protocol for diversity was designed after extensive literature review and later approved by concerned authority. It is designed to conduct an in-depth interview from open ended questions on phenomenological study of gender diversity giving a detailed description of the phenomenon being discussed.

\section{Data Collection Tool}

Data in qualitative research can be collected in six ways and the most commonly used in doing case studies are: interviews(semi structured, structured, open ended), observation which could be participant or non-participant point of view, documents, archival records and physical artifacts (Yin, 2009)

\section{Interview Protocol}

Interview is one of the most important sources of case study information. It is basically a guided conversation to get the detailed information about a phenomenon rather than structured questions. While interviewing it is necessary that the interview protocol is designed in such a manner that the line of inquiry to be maintained and also conversational questions reducing the biasness and leading towards the actual phenomenon (Yin, 2009).

In our case study an in-depth interview is conducted by HR managers and other relevant personnel. The duration of the interview was approximately last for one an half hour. It was open ended questions and one on one interview was conducted to share the ideas in a flexible manner with least constraints and to get the detailed description on gender diversity. Four broad questions (i) What do the respondent understand by gender diversity? (ii) How is gender diversity defined by the organization? (iii) How gender diversity has impacted the overall organizational culture and environment? and (iv) How gender diversity has impacted the respondent? Since a prior appointment for an interview was being set and a certain time is allotted so it started to as soon as I was being introduced to the interviewee by the concerned person through whom I had an access to the organization. The interview was recorded with the consent of the participant and memos were also written to record important facts and observations.

\section{Observation}

Case studies take place in natural setting of the case giving an opportunity for direct observation. The interview was conducted in a peaceful and quiet environment. While going towards the meeting room I observed that there were a number of female employees working and discussing matters with other colleagues both male and female in a very cordial and lively environment. I also visited the day care and the women's prayer area where proper cleanliness and hygienic factors were maintained.

Page $\mid 228$ 


\section{Documentation}

Documentary information is also a necessary for case studies. The documents help in getting detailed information about the phenomenon being discussed. It also provides an evidence of the data collected through other sources. In this research the documents are available on the company's website. Documents provide correct spellings and meanings of various terms used in the interview. It also provides other relevant and specific details which helps in making analysis and if the data does not corroborate with the documents then it gives further insight to inquire about the topic. In this case study the documents were reviewed first to get an overall idea of diversity in the organization and later the interview data was also compared for authenticity in the information. Since these documents are available on the company's website therefore the access is also easy as it can be referred as many times as needed.

\section{Principles of Data Collection}

The information gathered from the above sources can be maximized if the three principles of data collection were followed to establish the construct validity and reliability of the case study evidence (Yin, 2009).

\section{Triangulation}

The purpose of triangulation is to reach to the same conclusion from different sources to reach to a compatible solution. There are four types of triangulation at the time of evaluation. First is data triangulation where data is gathered from different sources. Second is investigator triangulation where the evaluations are being made among different investigators. Third is the theory triangulation where the same data set is used to have different perspectives and the fourth is the methodological triangulation where different methods used to come to the same conclusion. Contradiction is possible in all four types (Yin, 2009). Our research pertains to the first type of these four triangulations where data has been collected from multiple sources with an aim to present the same phenomenon or fact about the gender diversity in the organization.

\section{Case study database}

Case study database is created so that other researchers can view the evidences independently without making inferences from the written case study. This greatly enhances the reliability of the case study. The case study data base should provide sufficient information for any reader of the report to draw his own conclusions (Yin, 2009). In this case study also a data base has been created in the form of memos and notes which are being developed at the time of interviews and observations. These notes are hand written and can be made available on request. They are being written to comprehend a particular concept which later can be linked while analyzing the data. The answers to the open ended questions were also presented in narratives with a view to integrate evidence and also to show the complete coverage of the detailed information and facts about the diversity pertaining in the organization. The entire answer of the case study protocol is considered to be an integral part of the case study database.

\section{Chain of Evidence}

To maintain the reliability of information it is necessary have a chain of evidence which helps us in understanding the linkage of the research objectives, research questions and to the conclusions. 


\begin{tabular}{|c|c|c|c|}
\hline Research Objectives & $\begin{array}{l}\text { Research } \\
\text { questions }\end{array}$ & Findings & Evidence from the case \\
\hline $\begin{array}{l}\text { The objective of this } \\
\text { research is to interpret the } \\
\text { gender diversity as the } \\
\text { lived experience of the } \\
\text { respondents' through } \\
\text { phenomenological } \\
\text { hermeneutics in the } \\
\text { context of a Pakistani } \\
\text { organization }\end{array}$ & $\begin{array}{l}\text { How is gender } \\
\text { diversity defined in } \\
\text { the organization? } \\
\\
\text { How gender } \\
\text { diversity has } \\
\text { impacted the overall } \\
\text { organizational } \\
\text { environment and } \\
\text { culture? }\end{array}$ & $\begin{array}{l}\text { Implementation of } \\
\text { the gender diversity } \\
\text { plan } \\
\text { Managing gender } \\
\text { diversity }\end{array}$ & 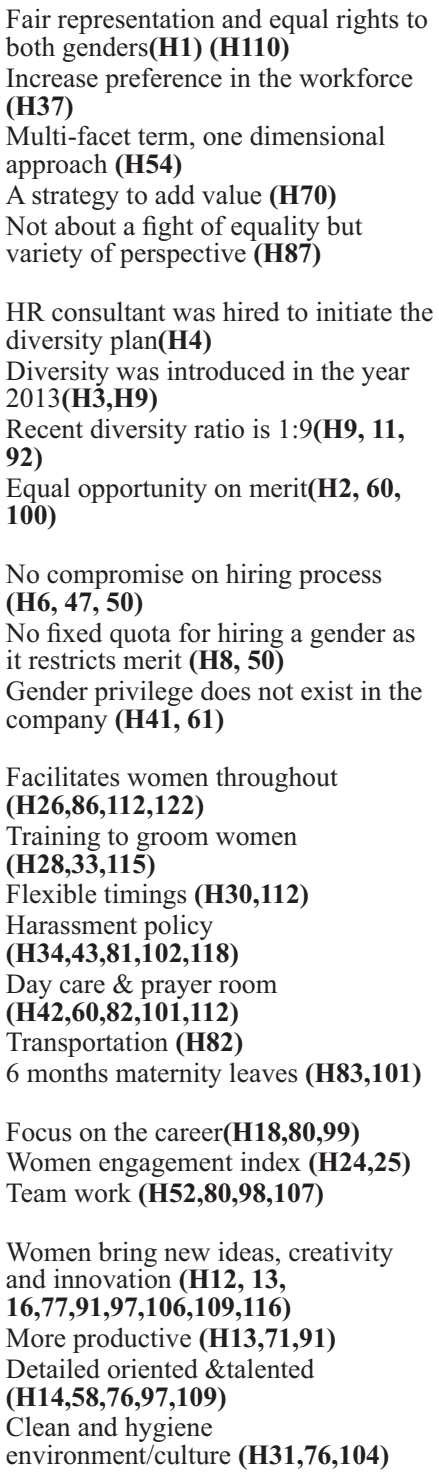 \\
\hline
\end{tabular}




\section{Implementation of the Gender Diversity Plan}

In response to question number 2 about defining of gender diversity from organization's point of view, diversity was introduced in the organizations in the year 2013 when it's moving into international markets. It was a top down approach when the top management and CEOs decided to address gender diversity first. Being an equal opportunity employer the company wants to have a lot of diversity for which they reviewed their policies and put statements that they cater all types of people. Diversity plan, started with the help of the HR Consulting Firm, which has worked with many international companies, had made successful plans to support gender diversity. The consulting firm strategized the road map of diversity by making a diversity council which comprised of all the senior people who have the vision, can set the objectives, and delegate it accordingly for implementation. The organizations seek external assistance from different organizations who can guide them on specific diversity. A lot of focus group was conducted to get the feedback of diversity initiatives from the employees and continuous sessions are being done with teams explaining diversity initiatives to make it a success with everyone's contribution. Frequent dialogue /communication with the employees were conducted to remove the mental barrier created over year. The company invites professional people on a panel discussion to talk about the benefits of having women at different levels and to make them a part of goal setting as well. Now many high tech organizations are also having women on board. Initially, the ratio of women to men was 1:12 but now it is coming down. Now it has gone up 9 to $10 \%$. Although the ratio was/is not much, the fact that companies are still working on gender diversity to bring a change is appreciable.

\section{Managing Gender Diversity}

In gender diversity, the company focuses on operational events which means doing things for the organization as a whole so that the men should not have a feeling of giving so much preferences to women i.e. encouraging one part and neglecting the other. According to a respondent, "The organization believes in moving forward together where men need to advocate as much as women need to advocate themselves. Men need to advocate for women as well."

Another respondent said: "They need to be champion on diversity." If all women are grouped together, it becomes women centered where they have a forum naturally to discuss kitchen, cooking, husbands and other household activities, so diversity makes it very professional.

Taking into consideration the similar viewpoint of all the respondents, gender diversity can almost only be a fair representation if it is based completely or mostly on merit. Equal opportunity i.e. hiring right person for the job so it does not mean that if a male candidate is good as compared to a female candidate who is average, you hire her to prove gender diversity in the organization. In the designated company, it is also found that it follows hiring procedures strictly on merit to the extent that if there are ten women and ten men and no women qualify while all the men do, they would not take any women at all, even if it slightly disrupts the gender diversity ratio. Even for promotions, factors like age, qualification and other parameters are looked upon and in this employee's own words, "Gender privilege doesn't exist in our company." In fact, because of such conformity to the policies of merit, the factor of less women induction comes in as less are able to qualify or meet the requirements of the particular job.

\section{Support for Women Employees}

According to surveys, studies and researches it was found that many a times women are skeptical and doubtful about their own decisions which stops them from being on the board of decisions. There is a trainer to train women on the concept of adaptive leadership where they are to improve their skills and work quality. They discuss the project with female employees stating all the consequences may it be tough or not and then it's their discretion to opt for such projects or not to avoid business. Women are 


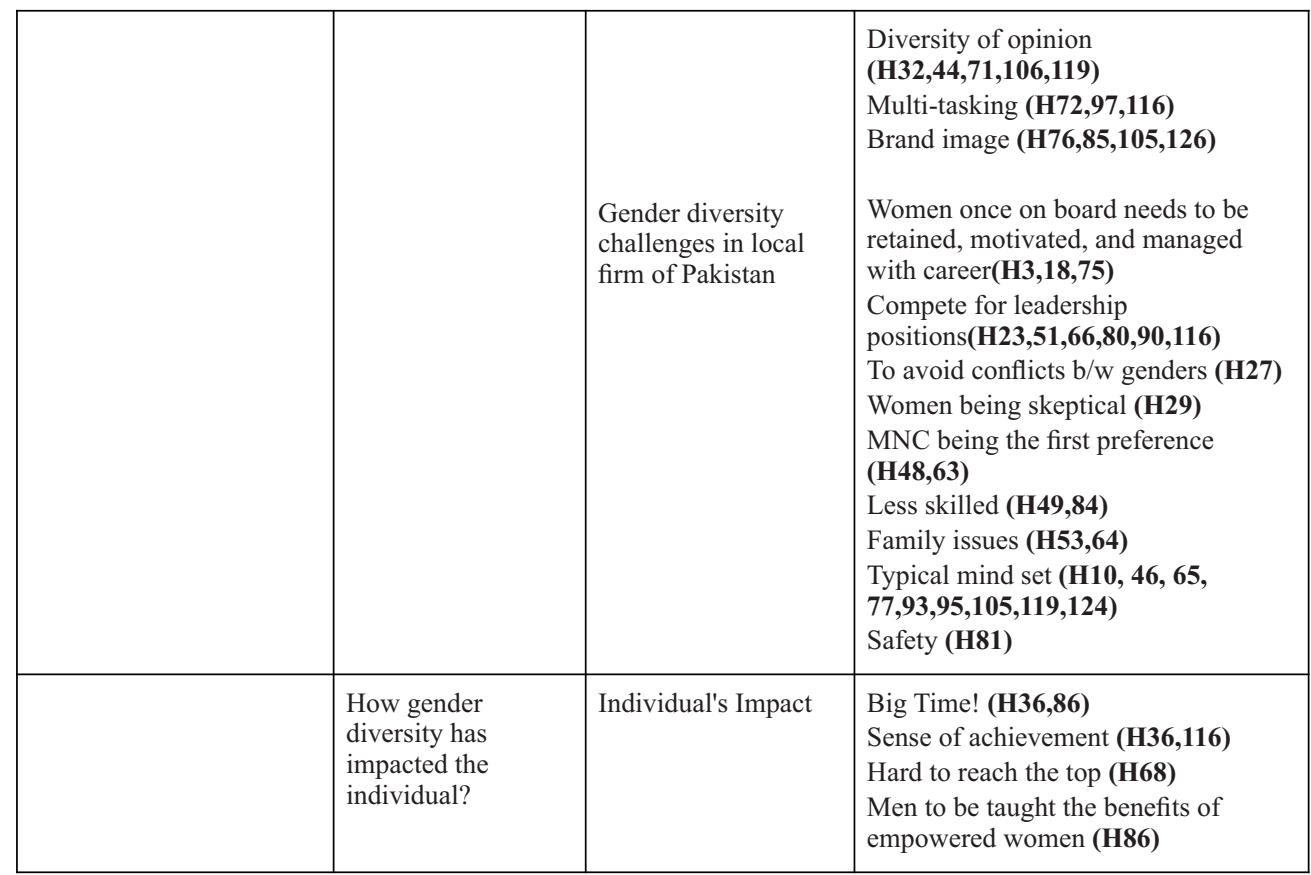

\section{DATAANALYSIS AND FINDINGS}

The data was collected through in-depth semi structured interview questionnaire to describe gender diversity and how is it felt by the respondent in their organization. One on one interview was conducted and also recorded during a specified period of time and were then transcribed verbatim. The reason for selecting the verbatim style of transcription is to explore the detailed description of gender diversity. After following Hycner's thematic methodology following categories were emerged from the interview to give a more detailed description of the phenomenon being discussed. The following paragraphs present these categories, staying as close to the respondent's words as possible.

\section{Gender Diversity}

With regards to my first question on respondents understanding of gender diversity, it was diversity with respect to gender is given substantial importance in the organization where it truly encourages a healthy balance of women at work place. It also means a fair representation and equal rights to both men and women. In the opinions of the respondents, diversity should not only be restricted to gender but should allow freedom of speech and thought to people from any background, be it religious or cultural. A respondent profoundly said: "Gender diversity means promoting women on merit and not taking them being woman as a weakness." Gender diversity is also referred to as a strategy where both genders (male and female) are promoted to add value to the organization. It is not a fight of equality but in nature we exist to complement each other which also throws light upon the topic of perspective brought in gender diversity; that will be further addressed. However, fair representation of such diversity is not the ratio of male and female employees but more towards how one gender should not empower the other(s) in terms of policies, rights or promotions as well as initiatives. This is also why gender diversity can be referred to as a rising concept in Pakistan as the argument of gender diversity.vs. merit is still held debatable, with companies supporting each side having concrete reasons of their own. 
being groomed on their overall professional presentation. These trainings are gender specific i.e. for women at all the different levels like senior and middle management. Trainings are being conducted to improve women in leadership qualities to make them competitive in the organization. These trainings also help them to better cope with any conflicts that may arise.

As women go with different phases of life the organization has a good support system to facilitate women like having day care centers for working mothers. The organization can't be unfair with a man working for 9 to 10 hours a day as compared to woman who works for 4 to 5 hours a day and goes home on time. So it takes care of both the genders to avoid conflicts. There are flexible timings for both the genders in case of any family issue or family commitment.

The part time work policy is being adopted by the company for both men and women. In fact, more men as compared to women have availed this policy which shows a positive sign that there is no discrimination and also a mind has been set there is no specific thing for women alone at work. It has been observed that majority women have joined back after their maternity leave. This shows a positive relationship with the employees of having a trust to be taken good care of. Women are hired in almost every department like finance, marketing, operations, managing branches, sales, support functions, relationship managers, customer services and others depending on their specialization. Another societal concern for women to not join the work force is the fear of any sort of harassment. Therefore, the organization has also enforced a very strict harassment policy. And, as said by a respondent, "There is a zero tolerance policy for harassment". This also resolves any fear of safety in the organization.

\section{Career Progression for women}

Once a woman is on board the organization has to retain her, motivate her, and manage her career. So hiring a wrong person would be a costly affair for the organization in terms of finance and overall performance of the company. The efforts are made to develop the current women employee to reach to the top management pool and should be able to compete for leadership positions. Women engagement index is the index to see how engaged are women and how do they feel to associate themselves with the organization. If they get another job, will they just walk away or consider the company to be an organization which is with them. The women engagement index came out as $77 \%$ result which was really good; shows that women are happy and satisfied to be a part of organization. Accordingly, to a female survey in the year 2013-2014 the company won the "Best employer of choice" award for two consecutive years. They have set targets which includes adoption rate on diversity policies, attrition rate of managers and women.

\section{Benefits of Gender Diversity}

In order to succeed across the world, the organization has to be diversity sampled. Other organizations do a lot of lip service by gathering female employees and listening to their issues and resolving them accordingly. But this organization believes in having a culture of women around and not to restrict them on secretarial positions. They focus on developing their career progression, path and also retain them.

Women on board bring a lot of new ideas which leads to innovation and creativity, which people of same gender and same mind-set don't come up with. Having women in teams, those teams are more productive, and give a more cut throat in completing and accomplishing the projects, because they bring in different thoughts and ideas. Three broad areas to focus on diversity and specifically gender diversity are

1. Talent

2. Innovation 
3. Creativity

Women are more detailed oriented which helps in progression of diversifying different products into the market. This mix of diversity means a lot in exploring new business, mainly because of more exciting or unique ideas. According to the viewpoint of a respondent, "Where men are considered to bring a lot of risk taking appetite women bring detailed orientation and together they do wonders, which make the organization to achieve its desired goals."

Gender diversity is a concept where organizations use as part of their strategy to promote efficiency, activities and ideas from both the genders as they bring different perspective and add value. Women bring a different set of qualities and competencies which many men do not. Women are capable of doing multi-tasking as where they are managing their house hold activities at the same time being able to perform at work also and still being able to achieve as same results as men. Organizations where this civilization exists prosper both in terms of being most favourite company to work for and the employer's grand is also projected very positively. Through this the company attracts talent, get better people and develop a conducive culture where both men and women work together for joint objectives and gain productivity that company benefits.

\section{Gender Diversity Challenges in the Local Firm of Pakistan}

The biggest challenge that a company is facing is that there is a typical mind set in our culture that women are born to look after the house and the family, so the acceptance on the part of men is poor yet, there are progressive minded families where the male is equally contributing in managing the house but it's really low. But, apart from men, females also develop a mindset of insecurity in working in a diverse company, despite knowing about policies/initiatives taken against such acts of harassment etc. or they fear having strict or firm leaders. As quoted by one of the respondents "Our problem is our mindset, we don't keep our window open".

Another great challenge that companies cannot overcome is the concept of gender diversity .vs. merit. In the experiences of some respondents, sometimes the lack of women in an organization is also the repercussion of the fact that less can qualify or present themselves capable enough to work as an employee or because of their unsure motives. Because of lack of women education and broad mindset of women, many tend to interview for a job with the same style that conforms them to society which stops them from reaching their true thought capabilities. Moreover, because society also focuses on a woman's fertility and marital factors more, many women tend to leave the organization after getting married (with the excuse of serving their husbands) or after having children (with the excuse of motherly attachment), giving the company some input, some (more) output and a loss overall, allowing them to think twice next time they hire a woman.

\section{Impact of gender diversity on an Individual}

In response to question number 4 about individual's impact due to gender diversity, one of the respondents, that technically spoke for almost all the others, "Gender diversity has impacted me big time."

Firstly, gender diversity has greatly encouraged women to work in the work force and also encouraged them to become more confident in society and brighter overall. It has given them a sense of achievement and a better purpose as well as responsibility in society. Moreover, the different perspectives of women and men has brought a break in the monotony of ideas and the contrast of opinion helps the organization to make more reasonable and better decisions. It also helps a person to develop learning skills as well as learn a lot because of such diversity as well as rationality of opinion and some topics appearing debatable also create the job atmosphere more exciting. And, hiring women on merit also gives them a sense of equality and achievement because they know that their 
gender was not and their capabilities were considered. Also, it brings a significant change in mindset of society as well as the opposite gender. Frequently working with men/women helps a person to break free of the stereotypical impression formed of the opposite gender. Therefore, women no longer constantly fear any type of harassment or uncomfortable behavior from men and neither do men consider women for house hold purposes only but acknowledge them as someone equally/more capable as compared to them. It teaches men to respect women and understand the benefits of women leadership or consideration.

However, where all the respondents satisfactorily responded to gender diversity's impact as a positive thing, one respondent had a different view of this initiatives product.

She felt that society's mindset, even though it is on the edge of acceptability, has not changed enough to understand the difference women can bring to the world. Referring to her own experience, she stated that women are considered, but a man's point of view would be taken first or would be considered better and more reassuring as compared to a women, even if they are saying the same thing. She also felt/feels it harder to climb the ranks than a man and has seen male employees newer or less experienced than her reaching leadership or even significant roles long before her, giving her so many valid reasons to support her views.

\section{Trustworthiness of Data}

The trustworthiness of the data will be established through triangulation where data is gathered from different sources to see whether all results in the same compatible conclusions. Secondly, the data has also been analyzed through Guba's model of trustworthiness (Lincoln and Guba Evaluation Criteria). The same data and analysis will be shared by the respondents again in order to avoid any biasness and misinterpretation of any facts.

\section{DISCUSSIONAND CONCLUSION}

Diversity was introduced in the case in the year 2013. Since then focus has been on emphasizing the current employees to be adaptable and flexible with the diversified group; be it gender, culture, persons with disability and other ethnic backgrounds. The idea is to have a culture where people are being respected and to make them part of the organization. The following discussion is based on the detailed interview with the HR managers, some of which have been specifically designated on diversity forum. Further discussion includes other employees, both on managerial and nonmanagerial level in the organization, and also on the information available on the website and other documents.

The research suggests that gender diversity not only brings great opportunity for organizations but at the same time a big challenge as discussed by Millikin \& Martins (1996) in Chapter 2 of Literature Review, and the respondents also claims that women also need to improve themselves in matters of pro-activeness, work life balance, openness to travel and accepting to work in male dominated areas or departments.

Male employees need to create the space for accommodating female employees and contribute towards making a congenial work environment to operate in. They need to understand that both genders are equal and gender diversification brings a different perspective towards operations as females have a different thought process. It is however observed that where companies have hired female employees, it has automatically resulted in improved organizational environment including the language, cleanliness and physical appearance of other employees. Although the organization emphasizes a lot on gender diversity but there are certain areas / jobs where still male employees are preferred like field sales jobs. Therefore my study suggests that as far as the mental block is concerned, 
it also needs to be understood that females may face work challenges and need to take up new challenges. My study further stresses on the point that they should not just refuse any work because it is a male dominated area, as it will result in further strengthening of the mental block which needs to be eliminated.

Gender diversity initiatives have also impacted the individuals as the encouragement has made them to become more confident in the society and provided a great sense of achievement and purpose. Females have been able to demonstrate their skills and abilities and in the process worked on different and important projects. They have been part of important initiatives and also climbed the ladder and reached senior positions. Additionally, the fear of harassment or uncomfortable behavior also goes away and females can work more freely. However, opinions still persist that certain females have found it challenging to be considered for senior positions and extra efforts are required to be considered relevant.

Organizations where this initiative exists prosper both in terms of being most favourite company to work for and the employer's brand is also projected very positively. Through this the company attracts talent, gets better people and develop a conducive culture where both men and women work together for joint objectives and gain productivity that company benefits.

Respondents believe that gender diversity initiative is a commitment and should be implemented in true spirit, rather than being done for publicity sake or just to show that as an organization you believe in gender diversity. The reason being, if it is not truly believed, then it will result in a lot of unrest among employees and also to their beliefs and loyalty towards the organization. Therefore, when implemented with commitment and a belief that it will assist in organizational performance, then only the results will follow as Robberson \& Park (2006) also believe.

For an efficient and sustainable diversity initiative, it is required that it is treated as an investment into business and not as an expense. Therefore, the linkage of the diversity initiative to the company's strategic goals is extremely critical i.e. making it as a business case. It should be taken as an initiative rather than a goal or objective. Therefore, the analysis of investment v/s returns would lead to an unconditionally accepted and adequately funded and supported diversity initiative (Robinson \& Dechant, Building a business case for diversity, 1997).

In short, I would say that in the present times organizations practicing gender diversity have better ratings and improved reputation amongst their competitors and also other sectors, because their environment focuses on fair treatment of individuals, encouraging them to grow and valuing its people and dignity. This can be related to the Stakeholder Theory which begins with the assumption that values are necessarily and explicitly a part of doing business. It asks managers to articulate the shared sense of the value they create, and what brings its core stakeholders together. It also pushes managers to be clear about how they want to do business, specifically what kinds of relationships they want and need to create with their stakeholders to deliver on their purpose (R. Edward Freeman, 2004). The theory addresses morals and values of the organization. It also argues that a firm should create value for its stakeholders. The stakeholder theory is related to our research to the extent that the organization also believed in creating and sharing values among its employees in the form of giving equal opportunity to both genders and giving an environment where both complement each other. The organization makes sure that all the employees are being respected and treated with due diligence and gives everyone room to grow.

As a researcher I believe that the organization subscribes to its commitment on implementation of gender diversity. Taking their human resource as an asset, the organization is bringing in gender diversity through a planned and systematic approach. The organization is cognizant of the fact that implementation of gender diversity cannot happen overnight and it's a big cultural shift which takes its own course and time. However, targeted efforts towards gender diversity has started showing its fruits 
and acceptance of gender diversity can be felt within and across the organization. Moreover, the organization strongly believes that the efforts need to continue as more and better fruits are yet to come. Therefore, focused efforts and initiatives need to continue and constant messages for mindset change need to continue also. This central theme seems to be running in my participant's responses and I also found after detailed review of my primary and secondary resources, that the organization is doing a sincere effort to comprehensively implement diversity at all hierarchal level.

\section{Managerial Implications}

This research has practical utility for firms who wish to initiate the concept of diversity in their organization because it will help them in overcoming the challenges faced in diversity implementation. These challenges include but are not limited to lack of acceptance of diversity, creating motivational balance among genders and work force retention. This case study will serve as a beacon for companies having a global vision to target a diverse customer base.

\section{Future considerations}

- Organizations need to identify the areas where diverse set of employees have not been included as part of workforce, and assign specific inclusion targets for such areas. Further a congenial environment should also be provided for all categories of people to work in.

The management needs to be make constant efforts to inculcate the concept of diversity within employees so that their acceptability is increased.

- Individuals need to also overcome their own mental barriers and show commitment to enter areas where typically diverse set of employees were not present e.g. females working in certain male dominated departments. This should assist in removing the mental barriers both for the organization and also for prospective entrants.

\section{REFERENCES}

Women@Telenor Pakistan.(2016).Retrieved April 2,2018, from telenor.com: https://www.telenor.com/media/inside-telenor/2016/women-telenor-pakistan/

Abbasi, M. U., Sohail, M., Cheema, F.-e.-A., \& Syed, N. A. (2013). Talent Management as success factor for organizational performance:A case of pharmaceutical industry of Pakistan. Journal of Management and Social Sciences 9(1), 14-23.

Ali, F., \& Syed, J. (2017). From rhetoric to reality:A multilevel analysis of gender equality in Pakistani organizations. Gender, Work and Organizations24(5), 472-486.

Amin, S., \& Ahmad, N. (2017). Ethnic diversity, social exclusion and economic determinats of crimes:A case study of Pakistan. Social Indicators Research, 1-20.

Ayub, N., \& Jehn, K. (2010). The diversity scenario in Pakistani organizations. 110-129.

Barrett, F. J., Powley, E. E., \& Pearce, B. (2011). Hermeneutic philosophy and organizational theory . Sociology of Organizations $32,181-213$.

Bassett-Jones, N. (2005). The paradox of diversity management, creativity and innovation . Diversity Management, Creativity and Innovation 14(2), 168-175.

Beechler, S., \& Woodward, I. C. (2009). The global war for talent. Journal of International Management 15, 273-285.

Bezrukova, K., Jehn, K. A., \& Spell, C. S. (2012). Reviewing diversity training: Where we have been and where we should go. Academy of Management 11(2), 207-227.

Boell, S. K., \& Cecez-Kecmanovic, D. (2010). Literature reviews and the hermeneutic circle. Australian Academics \& Research Liabriaries41(2), 129-144.

Bougie, R., \& Sekaran, U. (2010). Research Methods for Business A skill Building Approach.

Chadwick, K. D. (2003). Gender diversity in management and firm performance: The influence of 
growth orientation and organizational culture. Journal of Business Research 56, 1009 - 1019.

Channar, Z. A., Abbassi, Z., \& Ujan, I. A. (2011). Gender discrimination in workforce and its impact on the employees. Pak. J. Commer. Soc. Sci. 5(1), 177-191.

Chapple, L., \& Humphery, J. E. (2014). Does board gender diversity have a financial impact? Evidence using stock portfolio performance. Journal of Business Ethics 122(4), 709-723.

Creswell, J. W. (1988). Qualitative Inquiry and Research Design. New Delhi: Sage.

E.A.Jayne, M., \& L.Dipboye, R. (2004). Leveraging diversity to improve business performance: Research findings and recommendations for organizations. Human Resource Management 43(4), 409-424.

Ely, R. J. (1995). The power in demography: Women's social constructions of gender identity at work. Academy of Management 38(3), 589-634.

Ely, R. J., \& Thomas, D. A. (2001). Cultural diversity at work: The effects of diversity perspectives on work group processes and outcomes. Administrative Science Quarterly 46, 229-273.

Flood, A. (2013). Understanding Phenomenology. Nurse Researcher17(2), 7-15.

Francoeur, C., Labelle, R., \& Sinclair-Desgagne, B. (2008). Gender diversity in corporate governance and top management. Journal of Business Ethics, 83-95.

Gilbert, J. A., Stead, B. A., \& Ivancevich, J. M. (1999). Diversity Mnagement: A new organizational paradigm. Journal of Business Ethics 21, 61-76.

Herring, C. (2009). Does diversity pay? Race, gender and the business case for diversity. American Sociological Review74(2), 208-224.

Howell, K. E. (2013). An introduction to the philosophy of methodology. New Delhi: Sage.

Howell, K. E. (2013). An introduction to the philosophy oF methodology. London: Sage Publications Ltd.

Hycner, R. H. (1985). Some guidelines for the phenomenological analysis of interview data. Human Studies 8,279-303.

Idrees, R. N., Abbasi, A. S., \& Waqas, M. (2013). Systematic review of literature on workforce diversity in Pakistan. Middle-East Journal of Scientific Research 17(6), 780-790.

J.Ely, R. (1995). The power in demography:Women's social constructions of gender identity at work. Academy of Management 38(3), 589-634.

J.Ely, R., \& A.Thomas, D. (2001). Cultural diversity at work:The effects of diversity perspectives on work group processes and outcomes. Administrative Science Quarterly 46, 229-273.

Jayne, M. E., \& Dipboye, R. L. (2004). Leveraging diversity to improve business performance: Research findings and recommendations for organizations. Human Resource Management 43(4), 409-424.

Jayne, M. E., \& Dipboye, R. L. (2004). Leveraging diversity to improve business performance:Research findings and recommendations for organizations. Human Resource Management 43(4), 409-424.

Jones, B., \& Nigel. (2005). The paradox of diversity management, creativity and innovation. Creativity and Innovation Mnagement 14(2).

Joplin, J. R., \& Daus, C. S. (1997). Challenges of leading a diverse workforce. Academy of Management 11(3), 32-47.

Kafle, N. P. (2011). Hermeneutic phenomenological research method simplified . Bodhi: An Interdisciplinary Journal 5, 181-199.

Kochan, T., Bezrukova, K., Ely, R., Jackson, S., Joshi, A., Jehn, K., et al. (2003). The effects of diversity in business performance:Report of the diversity research network. Human Resource Management 42(1), 3-21.

Kochan, T., Bezrukova, K., Ely, R., Jackson, S., Joshi, A., Jehn, K., et al. (2003). The effects of diversity on business performance:Report of the diversity research network. Human Resource Management 42(1), 3-21.

Leary, B. J., \& Weathington, B. (2006). Beyound the business case for diversity in organizations. Employee Response Rights Journal.

Lincoln and Guba Evaluation Criteria. (n.d.). Retrieved from http://www.qualres.org/HomeLinc- 
3684.html

Lisowska, E. (2010). Gender diversity in the workplace. 42-46.

Lombardo, J. (n.d.). Age Diversity in the Workplace: Definition, Trends \& Examples. Retrieved March 29, 2018, from study.com: https://study.com/academy/lesson/age-diversity-in-theworkplace-definition-trends-examples.html

Lorbiecki, A., \& Jack, G. (2000). Critical turns in the evolution of diversity management. British Journal of Management 11, 17-31.

Marinova, J., Plantenga, J., \& Remery, C. (2010). Gender diversity and firm performance: Evidence from Dutch and Danish boardrooms.

Metzier, C. J. (2003). Ten reasons why diversity initiatives fail. Diversity in Practice 11(2).

Milem, J. F. (2002). The educational benefits of diversity: Evidence from multiple sectors.

Milliken, F. J., \& Martins, L. L. (1996). Searching for common threads: Understanding the multiple effects of diversity in organizational groups. Academy of Management 21(2), 402-433.

Milliken, F. J., \& Martins, L. L. (1996). Searching for common threads: Understanding the multiple effects of diversity in organizational groups. Academy of Management 21(2), 402-433.

Mirza, H. H., Mahmood, S., Andaleeb, S., \& Ramzan, F. (2012). Gender diversity and firm performance: Evidence from Pakistan. Journal of Social nd Development Sciences 3(5), 161-166.

Mirza, H. H., Mahmood, S., Andleeb, S., \& Ramzan, F. (2012). Gender diversity and firm performance: Evidence from Pakistan. Journal of Social and Development Sciemces 3(5), 161-166.

Mostret, N. (2007). Diversity of the mind as the key to successful creativity at Unilever. Creativity and Innovation Mnagement 16(1), 92-100.

Muhammad, R., NazarKhan, M., Babar, N., \& Qalb-e-Abbas. (2016). The Impact of Workforce Diversity Towards Employee Performance: Evidence from Banking Sector of Pakistan. Ameriacan Journal of Marketing Research2(2), 53-60.

Nguyen, T., Locke, S., \& Reddy, K. (2015). Does boardroom gender diversity matter? Evidence from a transitional economy. International Review of Economics and Finance 37, 184-202.

Noland, M., Moran, T., \& Kotschwar, B. R. (2016). Is gender diversity profitable? Evidence from a flobal survey.

Noon, M. (2007). The fatal flaws of diversity and the business case for ethnic minorities. Work Employment and Society 21(4), $773-784$.

Our diversity and inclusiveness agenda. (n.d.). Retrieved April 2, 2018, from engro.com: http://www.engro.com/our-diversity/

Patton, M. Q. (2015). Qualitative research and evaluation methods. New Delhi: Sage.

R. Edward Freeman, A. C. (2004). Stakeholder theory and the corporate objective revisited. Organization Science (15)3, 364-369.

Richard, O. C. (2000). Racial diversity, business strategy and firm performance: A resource based view. Academy of Management 43(2), 164-177.

Robberson, Q. M., \& Park, H. J. (2006). Examining the link between diversityand firm performance: The effects of diversity reputation and leader racial diversity. Cornell University ILR School.

Robinson, G., \& Dechant, K. (1997). Building a business case for diversity. Academy of Management11(3), $21-31$.

Robinson, G., \& Dechant, K. (1997). Building a business case for diversity. Academy of Management 11(3), 21-31.

Robinson, G., \& Dechant, K. (1997). Building a business case for diversity. Academy of Management11(3), 21-31.

S.W.Ng, E., \& Burke, R. J. (2005). Person-organization fit and the war for talent: does diversity management makes a difference? The International Journal of Human Resource Management 16, $1195-1210$.

Schur, L., Kruse, D., Blasi, J., \& Blanck, P. (2009). Is disability disabling in all workplaces? 
Workplace disparities and corporate culture. Industrial Relations 48(3), 381-410.

Shore, L. M., Chung, B. G., Dean, M. A., Singh, G., Ehrhart, K. H., Jung, D. I., et al. (2009). Diversity in organizations: Where are we now and where are we going? Human Resource Management Review 19, 117-133.

Silverman, D. (2013). Doing Qualitative Research. Singapore: Sage.

Stake, R. E. (1995). The Art of Case Study Research. New Delhi: Sage.

Stevens, F. G., Plaut, V. C., \& Sanchez-Burks, J. (2008). Unlocking the benefits of diversity: Allinclusive multiculturalism and positive organizational change. The Journal of Applied Behavirol Science 44 (1), 116-133.

Terjesen, S., Couto, E. B., \& Francisco, P. M. (2016). Does the presence of independent and female directors impact firm performance? A multi-country study of board diversity. . Journal of Management and Governance 20(3), 447-483.

Vegt, G. S., Vliert, E. V., \& Huang, X. (2005). Location-level links between diversity and innovatiove climate depend on national power distance. Academy of Management 48(6), 1171-1182.

Williams, K. Y., \& O'Reilly, C. A. (1998). Demography and diversity in organizations: A review of 40 years of research. Journal of Organizational Behavior 20,77-140.

Women's perspective. (n.d.). Retrieved April 2, 2018, from ShellPakistan.com: https://www.shell.com.pk/careers/diversity-inclusion/women-perspective.html

www.engro.com. (n.d.). Retrieved April 2, 2018, from http://www.engro.com

www.engro.com. (n.d.). Retrieved November 19, 2015, from Engro Corp: http://www.engro.com

www.hbl.com. (n.d.). Retrieved November 19, 2015, from http://www.hbl.com

Yin, R. K. (2009). Case Study Research . India: Sage. 